\title{
Short-term treatment of gonorrhoea with intramuscular and oral forms of trimethoprim- sulphamethoxazole
}

\author{
ALLAN LASSUS* AND OLLI-VEIKKO RENKONEN† \\ From the *Department of Dermatology and Venereology, University Central Hospital, Helsinki, and the \\ †Department of Immunology and Bacteriology, University of Helsinki, Finland
}

SUMMARY Fifty-nine male patients and 41 female patients with uncomplicated gonorrhoea were treated with an intramuscular dose of $1600 \mathrm{mg}$ sulphamethoxazole plus $320 \mathrm{mg}$ trimethoprim followed by an oral dose of $2400 \mathrm{mg}$ sulphamethoxazole plus $480 \mathrm{mg}$ trimethoprim 12 hours later. Forty-nine out of 52 male patients and 37 out of 38 female patients who were re-examined were cured. One of the men probably had a reinfection.

\section{Introduction}

Csonka and Knight (1967) reported favourable results with a combination of trimethoprim and sulphamethoxazole in the treatment of gonorrhoea. Later several studies confirmed these results. Recently an intramuscular form of trimethoprimsulphamethoxazole has been developed which gives high blood concentrations of short duration. To obtain a high blood level for at least 24 hours we prescribed one intramuscular dose of trimethoprimsulphamethoxazole and one oral dose 12 hours later to evaluate its effect on uncomplicated gonorrhoea in patients of both sexes.

\section{Material and methods}

The series included 59 male and 41 female patients with uncomplicated gonorrhoea. Specimens for direct microscopy and culture were taken from the urethra in men and from the urethra, cervix, and rectal mucosa in women before treatment and at the follow-up visit seven to 14 days later. The specimens for culture were transported in Stuart's medium to the laboratory and cultured on two Thayer-Martin media, one of which also contained trimethoprim. Although treatment was given on the basis of positive microscopical evidence, only cases confirmed by culture (including fermentation reac-

Address for reprints: Dr A. Lassus, Department of Dermatology and Venereology, University Central Hospital, Snellmanink 14, Helsinki 17, Finland

Received for publication 3 April 1978 tions) were included in the assessment. Sensitivity tests to penicillin $G$ and trimethoprim-sulphamethoxazole were carried out by the plate dilution method described by Reyn et al. (1958).

The treatment was given as an immediate intramuscular injection of two ampoules of Bactrim (Ro 6-2580/59, F. Hoffmann-La Roche and Co. AG, Basle, Switzerland) in equal doses into both gluteal regions, each ampoule containing $800 \mathrm{mg}$ sulphamethoxazole and $160 \mathrm{mg}$ trimethoprim.

Twelve hours later the patient was asked to take three tablets of Bactrim Quiksolv (Ro 6-2580/55, F. Hoffmann-La Roche and Co. AG, Basle, Switzerland) dissolved in a glass of water, each tablet containing $800 \mathrm{mg}$ sulphamethoxazole and $160 \mathrm{mg}$ trimethoprim.

\section{Results}

The MIC values for both penicillin $G$ and trimethoprim-sulphamethoxazole were estimated in 93 cases (Table 1). In nine cases the gonococci showed a slightly decreased sensitivity to trimethoprimsulphamethoxazole (MICs $=1 \cdot 25$ and $25 \mu \mathrm{g} / \mathrm{ml}$ ) and in 23 cases the MIC of penicillin $\mathrm{G}$ was $\geqslant 0.2$ $\mathrm{IU} / \mathrm{ml}$. There seemed to be no cross-resistance between penicillin $G$ and trimethoprim-sulphamethoxazole.

Ninety out of all 100 patients returned for re-examination, which showed that $49(94.2 \%)$ of the 52 men and $37(97 \cdot 4 \%)$ of the 38 women had negative culture results (Table 2). One of the male patients probably had a reinfection because he 
Table 1 Sensitivity-testing of 93 gonococcal strains to penicillin $G$ and trimethoprim-sulphamethoxazole

\begin{tabular}{|c|c|c|c|c|}
\hline \multirow[b]{2}{*}{$\begin{array}{l}\text { MICs of penicillin } G \\
(I U / m l)\end{array}$} & \multicolumn{3}{|c|}{ MICs of trimethoprim-sulphamethoxazole $(\mu \mathrm{g} / \mathrm{ml})$} & \multirow[b]{2}{*}{ Total } \\
\hline & $0 \cdot 31$ and $5 \cdot 3$ & 0.62 and 12.5 & $\begin{array}{l}1.25 \text { and } 25.0 \\
\text { (Slightly resistant) }\end{array}$ & \\
\hline$<0.1$ & 35 & 24 & 2 & 61 \\
\hline $0 \cdot 1$ & 5 & 3 & 1 & 9 \\
\hline 0.2 & 7 & 2 & 2 & 11 \\
\hline 0.5 & 4 & 4 & 3 & 11 \\
\hline $1 \cdot 0$ & 0 & 0 & 0 & 0 \\
\hline $2 \cdot 0$ & 0 & 0 & 1 & 1 \\
\hline Total & 51 & 33 & 9 & 93 \\
\hline
\end{tabular}

Table 2 Treatment results with trimethoprim-sulphamethoxazole given in a single intramuscular dose $(1600 \mathrm{mg}+320 \mathrm{mg})$ and a single oral dose $(2400 \mathrm{mg}$ and $480 \mathrm{mg}) 12$ hours later

\begin{tabular}{|c|c|c|c|c|}
\hline \multirow[b]{2}{*}{ Patients } & \multicolumn{3}{|c|}{ MICs of trimethoprim-sulphamethozaxole $(\mu \mathrm{g} / \mathrm{ml})$} & \multirow[b]{2}{*}{ Total } \\
\hline & $\leqslant 0.62$ and 12.5 & $1 \cdot 25$ and $25 \cdot 0$ & Not known & \\
\hline \multirow{2}{*}{\multicolumn{5}{|c|}{$\begin{array}{l}\text { Treated ( } 59 \text { men, } 41 \\
\text { women) }\end{array}$}} \\
\hline & 84 & 9 & 7 & 100 \\
\hline Re-examined & 77 & 8 & 5 & 90 \\
\hline Cured & 76 & 5 & 5 & 86 \\
\hline Treatment failures & 0 & 3 & $\mathbf{0}$ & 3 \\
\hline Reinfections & 1 & 0 & 0 & 1 \\
\hline
\end{tabular}

admitted sexual contact following treatment and harboured gonococci which were highly sensitive to trimethoprim-sulphamethoxazole. All the remaining three patients with positive culture results on re-examination had gonococci which were slightly resistant to trimethoprim-sulphamethoxazole, and they denied sexual contact following treatment. Thus, it seems probable that these patients (one woman and two men) were true treatment failures. Thus, of the 90 patients who were re-examined $3.3 \%$ were treatment failures. Three $(33.3 \%)$ of the nine patients with a slightly decreased sensitivity to trimethoprim-sulphamethoxazole (MICs $=1 \cdot 25$ and $25 \mu \mathrm{g} / \mathrm{ml}$ ) were treatment failures.

The only side effect observed during the study was pain at the injection site in one patient; this disappeared after two days.

\section{Discussion}

The sensitivity-testing of the gonococci in the present study showed that fewer than $10 \%$ of the tested strains had a slightly decreased sensitivity to trimethoprim-sulphamethoxazole. The decreased sensitivity did not seem to cross-react with the decreased sensitivity to penicillin, which was about
$25 \%$ in the present series. It seems, therefore, that trimethoprim-sulphamethoxazole is a good substitute in cases in which penicillin is ineffective.

It seems evident that the plate dilution technique for trimethoprim-sulphamethoxazole gives adequate information on the clinically valuable sensitivities of gonococci for trimethoprim-sulphamethoxazole, at least with the present treatment schedule. All treatment failures (three patients) were infected by strains with MIC values of 1.25 and $25 \mu \mathrm{g} / \mathrm{ml}$ for trimethoprim-sulphamethoxazole, but no cases of treatment failure occurred in the group of patients with more sensitive gonococci.

The side effects were minimal; no allergic rashes were seen and only one patient had severe pain at the injection site.

Thus, the one-day treatment schedule we used for cases of uncomplicated gonorrhoea seemed to be effective and safe in patients of both sexes.

\section{References}

Csonka, G. W., and Knight, G. J. (1967). Therapeutic trial of trimethoprim as a potentiator of sulphonamides in gonorrhoea. British Journal of Venereal Diseases, 43, 161-165.

Reyn, A., Korner, B., and Bentzon, M. W. (1958). Effects of penicillin, streptomycin, and tetracycline on $N$. gonorrhoeae isolated in 1944 and in 1957. British Journal of Venereal Diseases, 48, 517-521. 